\title{
Electrical Conductivity and Thermodynamic Studies on Sodium Diethyldithiocarbamate in Methanol at Different Temperatures
}

\author{
Nasr Hussein El-Hammamy ${ }^{*}$,Haitham Ahmed El-Araby \\ Chemistry Department, Faculty of Science, Alexandria University, P.O. 426 Ibrahimia,Alexandria, \\ 21321, Egypt. \\ *E-mail: nasrelhammamy@yahoo.com
}

doi: $10.20964 / 2016.10 .23$

Received: 25 May2016/ Accepted: 31 July 2016 / Published: 6 September 2016

\begin{abstract}
The conductance data of sodium diethyldithiocarbamate (NaDDC) in methanol at different temperatures $\left(25,30,35\right.$ and $\left.40^{\circ} \mathrm{C}\right)$ are presented. Results were construed by applying the FuossOnsager equation to determine the characteristic parameters: equivalent conductance at infinite dilution $\Lambda_{0}$, association constant $\mathrm{K}_{\mathrm{A}}$, the distance of closest approach of ions å. After calculation of the electrostatic Stokes' radii $\left(\mathrm{R}^{+}\right.$and $\left.\mathrm{R}^{-}\right)$, their sum is likened to å value. Thermodynamic functions such Gibbs free energy change $\Delta \mathrm{G}^{\mathrm{o}}$, enthalpy change $\Delta \mathrm{H}^{\mathrm{o}}$, change in entropy $\Delta \mathrm{S}^{\mathrm{o}}$ and the activation energy $\left(\Delta \mathrm{E}_{\mathrm{s}}\right)$ were estimated.
\end{abstract}

Keywords: Sodium diethyldithiocarbamate, equivalent conductance at infinite dilution $\left(\Lambda_{\mathrm{o}}\right)$, ion association, activation energy and thermodynamic functions.

\section{FULL TEXT}

(C) 2016 The Authors. Published by ESG (www.electrochemsci.org). This article is an open access article distributed under the terms and conditions of the Creative Commons Attribution license (http://creativecommons.org/licenses/by/4.0/). 